\title{
AUTOMATIC SYSTEM FOR PHYTOPLANKTONIC ALGAE IDENTIFICATION
}

\author{
José Luis Pech-Pacheco ${ }^{1,2}$, Gabriel Cristobal' , Josué Álvarez-Borrego ${ }^{2}$ and Leon Cohen ${ }^{3}$ \\ ${ }^{1}$ Instituto de Optica (CSIC). Serrano 121. 28006 Madrid. Spain. ${ }^{2}$ División de Fisica Aplicada, Departamento de \\ Óptica (CICESE). Km 107 Carretera Tijuana-Ensenada, Ensenada baja California, México. 'Hunter College and \\ Graduate Center of CUNY. 695 Park Avenue, NY 10021
}

\begin{abstract}
We propose an automatic system for diatom localization and identification with a modular structure. The main contribution of this work is to provide a complete automatic system for the analysis of phytoplanktonic samples in brightfield microscopy. The overall procedure consists in two parts: first, frame gathering at low magnification and second, further analysis at higher magnification. At low magnification the goal is to obtain a panoramic overview of the full sample by tiling each frame. Subsequent processing steps will provide the localization and size of each particle in each frame for further analysis. The localization method based on image fusion techniques provides more robust and accurate particle detection than other methods reported in the literature. From the size information we obtain a useful cue about the objective to use. At higher magnification we developed new autofocusing techniques providing a fast and accurate focused image. Because particles present a volumetric structure, we propose the use of multifocus fusion techniques for merging in a single plane the focused parts from neighbouring the best focused image. Then we applied a particle selection analysis to reduce the number of images to analyze, i.e. to discriminate diatoms from debris. This is the most challenging step, due to large variability of shapes, diatom fragmentation, particle overpopulation and diatom hiding. The latter is not described in the present paper and will be the subject for a forthcoming publication. Finally, for diatom identification we use the scale transform technique and a cepstrum-based cross-correlation technique.
\end{abstract}

Keywords: automatic slide scanning, identification, registration, cepstrum analysis.

\section{RESUMEN}

Se propone un sistema automático con una estructura modular para la localizacidn e identificacidn de diatomeas . La contribucidn principal del presente trabajo es proporcionar un sistema automático completo para el análisis de muestrus fitoplactdnicas en microscopia de transmisidn. El procedimiento general consiste en dos partes: en primer lugar, la adquisicidn de imdgenes en bajos aumentos y una segunda fase de analisis a aumentos mayores. En bajos aumentos el objetivo es obtener una visidn panorámica de la muestra completa por medio de un mosaico de los diferentes campos, de manera que en etapas sucesivas de procesado pueda determinarse la localizacidn y tamaño de cada partícula para su posterior analisis. El me'todo de localizacidn esta basado en la utilización de te'cnicas de fusión, proporcionando una mas robusta y precisa deteccidn de las particulas que otros métodos descritos en la literatura. La informacidn del tamaño, extraida en esta etapa, proporciona una clave fundamental a la hora de elegir el tipo de objetivo a utilizar en mayores aumentos. Para estos últimos aumentos, proponemos la utilizacidn de nuevas te'cnicas de autoenfoque que proporcionan de una manera rápida la mejor imagen enfocada. Dado que las particulas presentan una estructura volume'trica, se propone el uso de te'cnicas de fusión de imágenes multifoco, para presentar en un simple plano las partes enfocadas de los planos cercanos a la imagen de mejorfoco. A continuacidn se efectúa un proceso de seleccidn de particulas para reducir el numero de imágenes a analizar, es decir, con objeto de realizar una discriminacidn del tipo diatomea-materia residual. Esta ultima etapa presentu una gran dificultad, debido a la gran variabilidad de formas, a la fragmentacidn de diatomeas, a la superpoblacidn de particulas y a la superposicidn de células. Esta ultima parte queda fuera del alcance del presente articulo y sera objeto de una prdxima publicacidn. Finalmente, paru el proceso de la identificacidn de diatomeas se han usado técnicas basadas en la transforrnada de escala y te'cnicas de correlacidn cruzada a través del cepstrum.

Palabras clave: Análisis automático de muestras, identificacidn, registro, analisis cepstral. 


\section{INTRODUCTION}

Although some studies have looked at the analysis of images at medium magnification, they do not consider the problem a step ahead i.e. starting the automatization process from a single (or a few) low-medium magnification images. This is a very challenging problem, because the sample may be contaminated with debris or it may even contain broken specimens. We identify two broad classes of diatom identification systems: semiautomatic and automatic. Semiautomatic methods require human interaction to select initial specimens from a low resolution image. Obviously, this group of methods provides good results but it is time-consuming and tedious. Methods for diatom detection and identification have been studied in Cairns et al.,1972; Cairns et al., 1979; Culverhouse et al., 1996 and PechPacheco \& Alvarez-Borrego, 1998. Cairns et al. (1972) have proposed some diatom identification methods based on coherent optics and holography. However, they do not tackle the problem of the automatization of low resolution images. Culverhouse et al.( 1996) derived some methods for phytoplankton identification based on neural networks but, again, they do not provide a fully automatic method. Pech-Pacheco \& ÁlvarezBorrego, (1998) have proposed a hybrid opticaldigital method for identification of five different species of phytoplankton through the use of operators invariant to translation, rotation and scale. In Pech-Pacheco et al.( 1999) correlation techniques were used for identification of phytoplankton specimens. At low magnification it is hard to perform a diatom/non-diatom discrimination. Therefore it is necessary to detect all possible "candidate" particles through image thresholding. A few methods have been proposed in the literature for threshold determination. We propose a simple but efficient method based on a modified histogram thresholding. We propose an adaptive thresholding method providing a good compromise between detectability and noise rejection, based on the use of the "triangle method" described in Zack et al., (1977). One key aspect in the automatization process is to determine reliable and fast autofocusing methods. Groen et al. (1985) identified eight different criteria for comparing autofocus algorithms. Many focusing techniques have been proposed in the literature (Bocker et al., 1996; Krotkov, 1987; Nayar \& Nakagawa, 1994; Subarao \& Nikzad, 1993; Yeo et al., 1993). Most of them extract a focus measure giving a maximum for the best focused image. Defocus algorithms can be classified into two categories. In the first, algorithms are based on the statistical variance of pixel values, while in the second they are based on the spatial-frequency content of the image. Also, two new autofocusing algorithms based on the computation of the variance of the image gradient, or Laplacian image, outperform existing methods, according to some novel feature focus metrics.

We propose an automatic system for diatom localization and identification with a modular structure. The overall procedure consists in two parts. In the first, frames are gathered at low magnification. In the second part, further analysis is performed at higher magnification. At low magnification the goal is to obtain a panoramic overview of the full sample by tiling each frame. Then, each frame is processed, to obtain the localization and size of each particle for further analysis. At higher magnification we developed new autofocusing techniques providing a fast and accurately focused image. Because the particles present a volumetric structure, we proposed the use of multifocus fusion techniques. We then applied a particle selection analysis to reduce the number of images to analyze, i.e. to perform a diatom-debris discrimination. The exact procedure is out of the scope of the present paper and will be described in a forthcoming publication. The last part of the system is an identification algorithm based on cross-correlation techniques. For the latter, we propose an affine invariant system based on the use of both the scale transform technique and a cepstrum-based cross-correlation technique. Cepstrum analysis has been used for acoustic signal processing, Doppler analysis, shift detection and stereo image analysis (Lee et al., 1988; Lee et al., 1989; Voss et al., 1999; Yeshurum \& Schwartz, 1989). However, there 
are few works on the use of cepstrum analysis for image registration. The main advantages of the cepstral techniques are noise tolerance and high discrimination for similar objects.

\section{MATERIALS AND DATASET}

Different diatom samples from fresh water were analyzed with a Zeiss Axiophot photomicroscope illuminated with a $100 \mathrm{~W}$ halogen light with X10, X20, X40 and X100 lenses. For image acquisition, we used a Scion frame grabber with the NIH image processing shareware connected to a CCD analog camera from Cohu. Two separate $\mathrm{PC}$ image analysis systems (Pentium II, III) were used for image acquisition and for algorithm computation. Furthermore, for computer intensive calculations a SUN Enterprise 450 with four processors was used. Images were digitized to $256 \times 256 \times 8 \mathrm{bit} / \mathrm{pixel}$ for a more efficient use of the Fourier methods. The microscope slide was controlled with a X-Y-Z motorized stage from Prior Scientific, with a step size of $0.1 \mu \mathrm{m}$ for the $\mathrm{X}-\mathrm{Y}$ axis and $0.01 \mu \mathrm{m}$ for the Z-axis. Figure 1 shows a schematic overview of the system configuration used for automatic slide scanning. The range of particles analyzed was between 20 and 260 microns, considered part of the "microplankton". Smaller diatoms ("nanoplankton") could not be observed using the previously described configuration, and require the use of oil-immersion objectives. The ocular magnification was X0.6. The size range of the particles observed were as follows: i) for X10, size range $=131-260$ microns; $i i)$ for $X 20$, size range =61-130 microns; iii) for $\mathrm{X} 40$, size range $=20$ 60 microns. In further studies we will consider the extension of the present study to the nanoplankton size range.

\section{AUTOMATIC LOCALIZATION OF MICROSCOPIC PARTICLES}

The overall procedure consists in two parts. First, frame gathering at low magnification and, second, further analysis at higher magnification. At low magnification the goal is to obtain a panoramic overview of the full sample by tiling each frame. Subsequent processing steps will provide the localization and size of each particle in each frame for further analysis. Figure 2 shows a schematic overview of the system processing

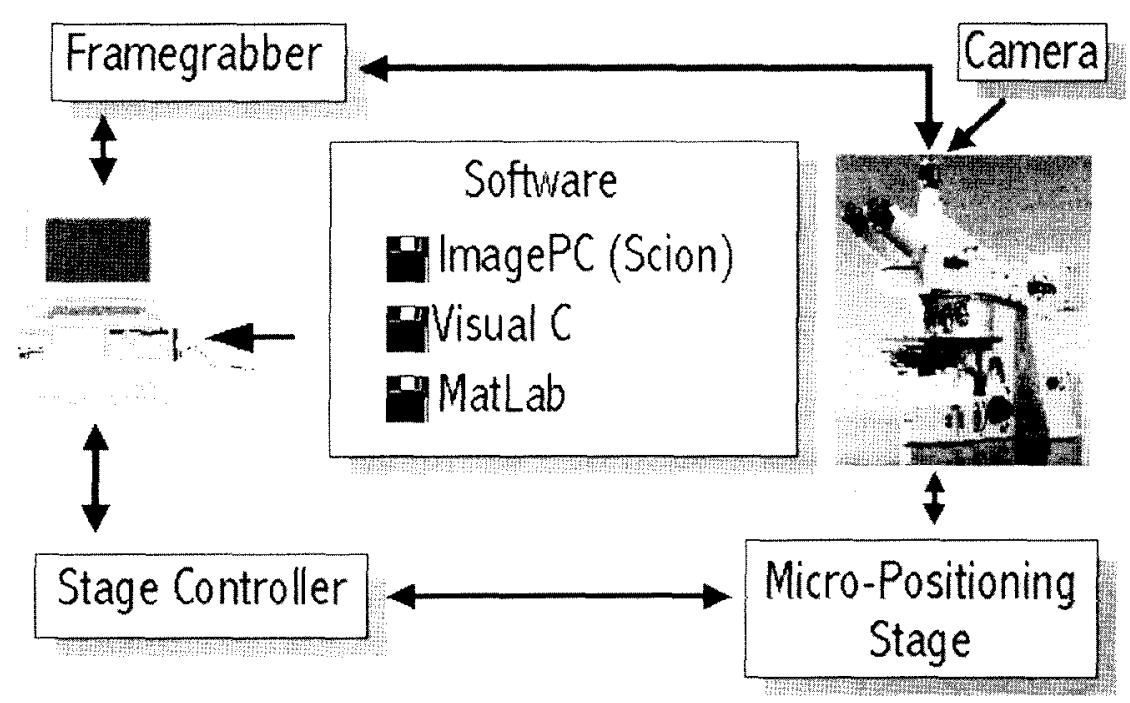

Figure 1. System configuration for automatic slide scanning. Configuración del sistema para escaneado automático de muestras. 


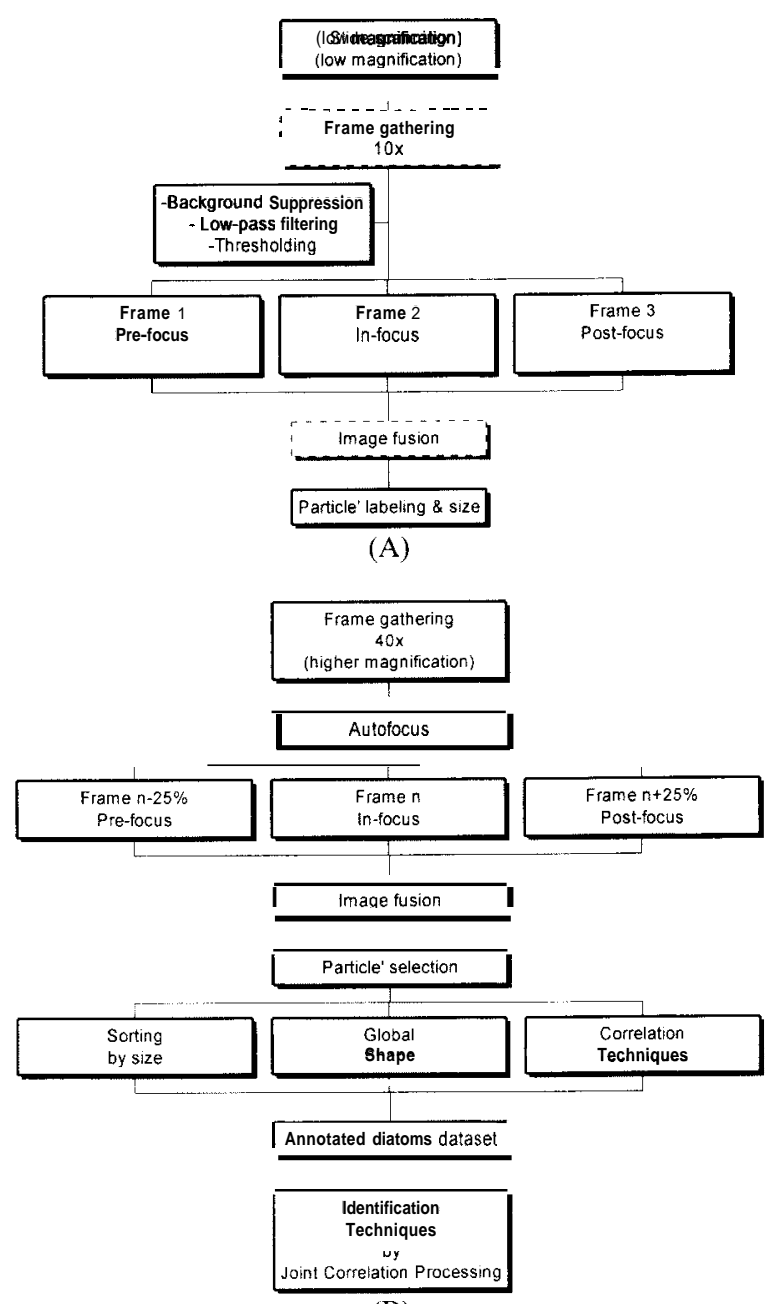

(B)

Figure 2. Schematic overview of the processing stages of the system. (a) Processing stages at low magnification; (b) Processing stages at higher magnification. Representación esquemática de las etapas de procesado del sistema. (a) Procesamiento en bajo aumento; (h) Procesamiento en alto uumento.

stages (Fig. 2a, at low magnification and Fig. 2b at higher magnification). The location method is based on image fusion techniques and provides a more robust and accurate particle detection than other methods in the literature. From size information we obtain a useful cue about which objective to use. At higher magnification we developed new autofocusing techniques that provide a fast and accurately focused image. Because particles

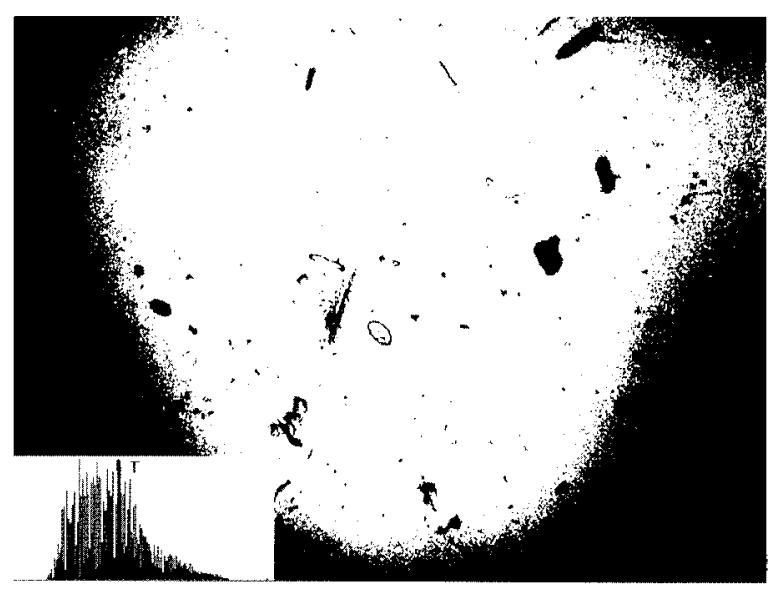

(a)

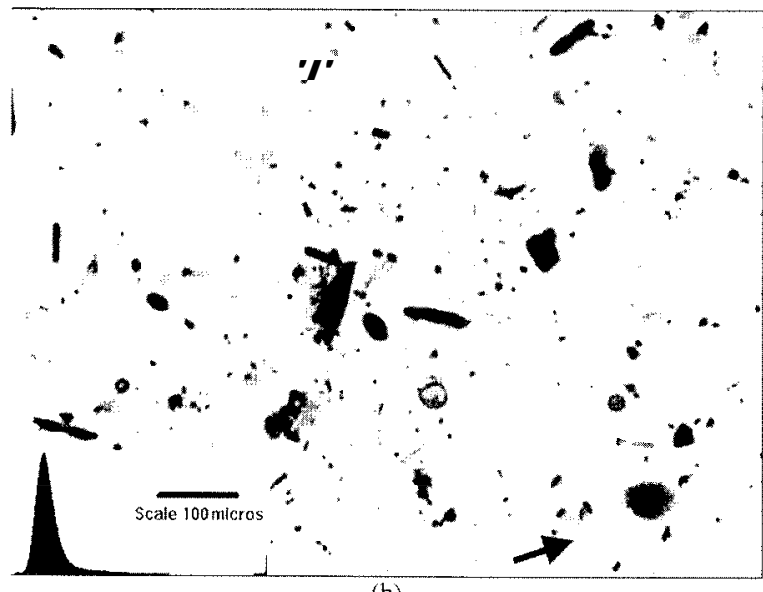

(b)

Figure 3. (a) Histogram Thresholding. Note the unequal illumination effect; (b) background corrected (top-hat algorithm) after lowpass filtering. Note the histogram change (lower left inset). (a) Umbralización del histograma. Ohse'rvese el ejecto de iluminación no homogénea (b) Corrección de fondo (algoritmo "top-hat") después del filtrado paso-bajo. Obsérvese el cambio en la forma del histograma (imagen insertada ahujo a la izquierda)

present a volumetric structure, we propose the use of multifocus fusion techniques for merging in a single plane the focused parts neighbouring the best focused image. Then we applied a particle selection analysis to reduce the number of images to analyze, i.e. to discriminate diatoms from debris. Here we describe the slide scanning, autofocusing and particle identification methods. The diatom-debris discrimination procedure will 
be subject for a forthcoming publication.

\section{Slide scanning}

Diatom detection is based on the use of graylevel histogram manipulation techniques oriented to obtain the centroid position of areas of interest. Figure 3a shows one example of a low- magnification image $(10 \mathrm{x})$ with some diatom specimens and some debris. At this resolution it is hard to discriminate between diatom and non-diatom objects. Our main goal is to provide an estimate of the centroid position of each sample to be analyzed at higher magnification. Following is a detailed description of the automatic slide scanning methods.

\section{Mosaic frame sampling.}

At low magnification it is necessary to arrange all fields as a multi-frame mosaic, this will allow to identify the positions of "candidate" particles. In general, an effect of unequal illumination between frames can be observed. This effect can be eliminated by a background suppression method using a top-hat algorithm (Russ, 1995).

\section{Multiframe detection}

Because specimens may be observed at different depth planes, we tested different algorithms for object detection. In particular, we used a simple fusion technique for detecting particles that might appear at different depth planes. In this technique the focused plane is merged with a few neighbouring planes. For a thorough review of image fusion techniques see Rockinger (1999).

\section{Threshold determination.}

A few methods have been proposed in the literature for threshold determination. For a good summary see Kindratenko (1997). It is by far the most
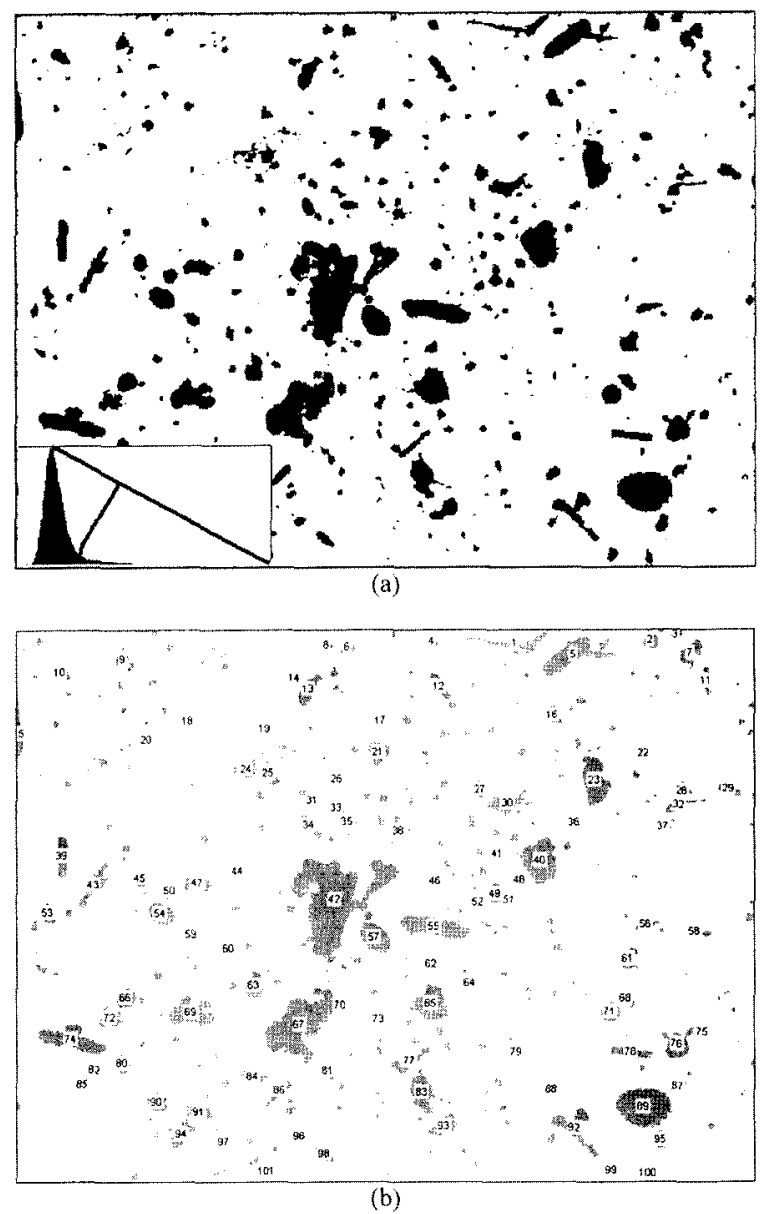

Figure 4. (a) Binarized image after application of the "triangle"thresholding method. Note the adaptive threshold value marked by an arrow (lower left inset); (b) Labelled particles after fitting a parallelogram to its outline. (a)Imagen binarizada según el me'todode umbralización del triangulo. Obsérvese el valor adaptutivo del umbral marcudo mediante una flecha en el histograma de la izquierda (abajo). (b) Partículas etiquetadas después de unajuste de formas a través del método del "paralelogramo".

complex process as it is necessary to simultaneously account for multiple effects, e.g. unequal illumination, large variability of image profiles, etc. At low magnification it is hard to distinguish diatoms from debris. Therefore it is necessary to detect all possible "candidate" particles. Once the particles have been detected by applying image processing techniques, we extract their positions and sizes. We have evaluated the influence of 
threshold selection on particle detection. The "triangle method" provides a simple and adaptive method of particle detection (Zack et al, 1977). Figure $3 \mathrm{a}$ shows that the result of the binarization process is not generaly effective. In this process a threshold value $\mathrm{T}$ located at midway distance between the histogram extrema is located (see inset located at lower left in Fig. 3a). We can observe an effect of unequal illumination in this image. To overcome the shortcomings of a nonuniform illumination, we performed two operations over the original image. i) background correction by a top-hat (or "rolling ball") technique (Russ, 1995). In a top-hat filtering operation those pixels that exceed the crown are considered noise and are replaced by the mean or the median value of the hat's brim. The "rolling ball" method considers the darker pixels as the target to remove. ii) a low pass filtering on the resultant image. Figure $3 \mathrm{~b}$ shows that the histogram of the resultant image presents a Gaussian-like shape allowing application of "the triangle" algorithm (see inset at lower left). Figure $4 \mathrm{a}$ shows that the binarization provides an effective particle detection method, even with particles presenting extreme gray level values (see the rod-shape particle at bottom right side of figure $4 \mathrm{~b}$ ). Note that the resultant outlines do not necessarily delineate well the particles due to the low-pass smoothing operation (Fig. 4a). However, this not a real trade-off because what really counts is the centroid determination which will then be used at further magnification. Figure $4 \mathrm{~b}$ shows the image with particles labelled and which are suitable for analysis at higher magnification. We have also implemented a "particle" location method guided by size, i.e. a selective searching process for detecting those particles that fall off a specific size range. This process can be considered a particle screening method although debris cannot be removed using this technique.

\section{Autofocusing}

We have evaluated different focus criteria and selected those four that perform best.
Local variance

Let us assume a stack of $\mathbf{k}$ images of size NxM taken by changing the microscope focus in steps of $1 \mu \mathrm{m}$. Figure 5 shows some examples of the image stack with the best focused image located at the center of the image. The local variance at point $(\mathrm{n}, \mathrm{m}), \mathrm{n}=1, \ldots, \mathrm{N}$ and $\mathrm{m}=1, \ldots, \mathrm{M}$ is given by:

$$
F_{c i}(n, m)=\frac{1}{w_{x} w_{y}} \sum_{j=0}^{w_{x}} \sum_{j=0}^{w_{k}}\left[f_{k}(n+i, m+j)-f_{k}(n . m)\right]^{2}
$$

where $f_{k}$ represents the mean value of the frame $f_{k}$, and $w_{x} w$, the window size:

$$
f_{k}(m, n)=\frac{1}{w_{x} w_{y}} \sum_{i=0}^{w_{x}} \sum_{j=0}^{w_{y}}\left[f_{k}(m+i, n+j)\right]
$$

The final focus measure will be given by the global variance of the previous local variance image:

$$
F_{v a r}^{(k)}=\frac{1}{N M} \sum_{m=0}^{M} \sum_{n=0}^{N}\left[l v_{k}(m, n)-l v_{k}(m . n)\right]^{2}
$$

where $f m_{k}{ }^{v}$ gives the focus measure for the image $k$ and $l v_{k}$ is the global variance value:

$$
l v_{k}=\frac{1}{N M} \sum_{m=0}^{M} \sum_{n=0}^{N}\left[l v_{k}(n . m)\right]
$$

\section{Variance ojgradient magnitude}

The use of image gradients (either the first or second derivatives) are instrumental in order to determine a reliable focus measure. In particular, the Tenengrad method is considered as a benchmark in this field (Krotkov, 1987). The method is based on computing the gradient magnitude of a Sobel operator (Russ, 1995):

$$
g_{k}(n, m)=\sqrt{g_{x}(n, m)^{2}+g_{y}(n, m)^{2}}
$$




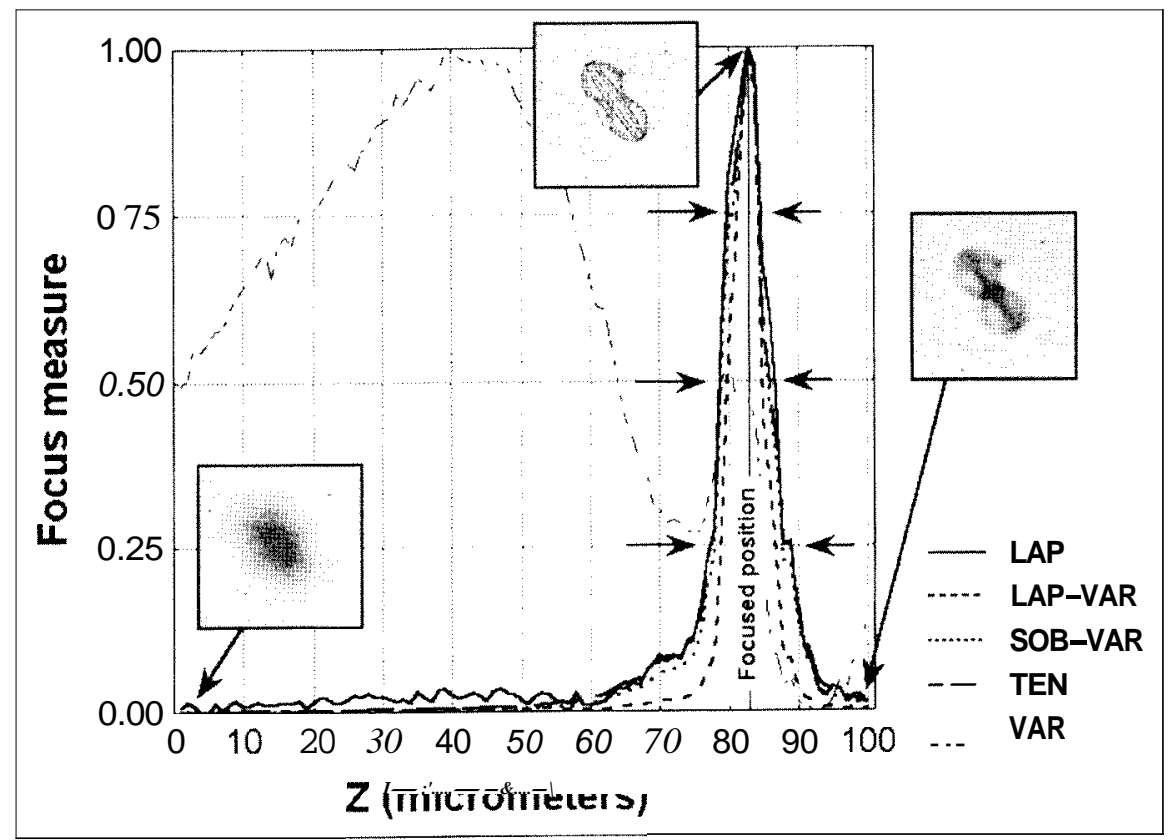

(a)

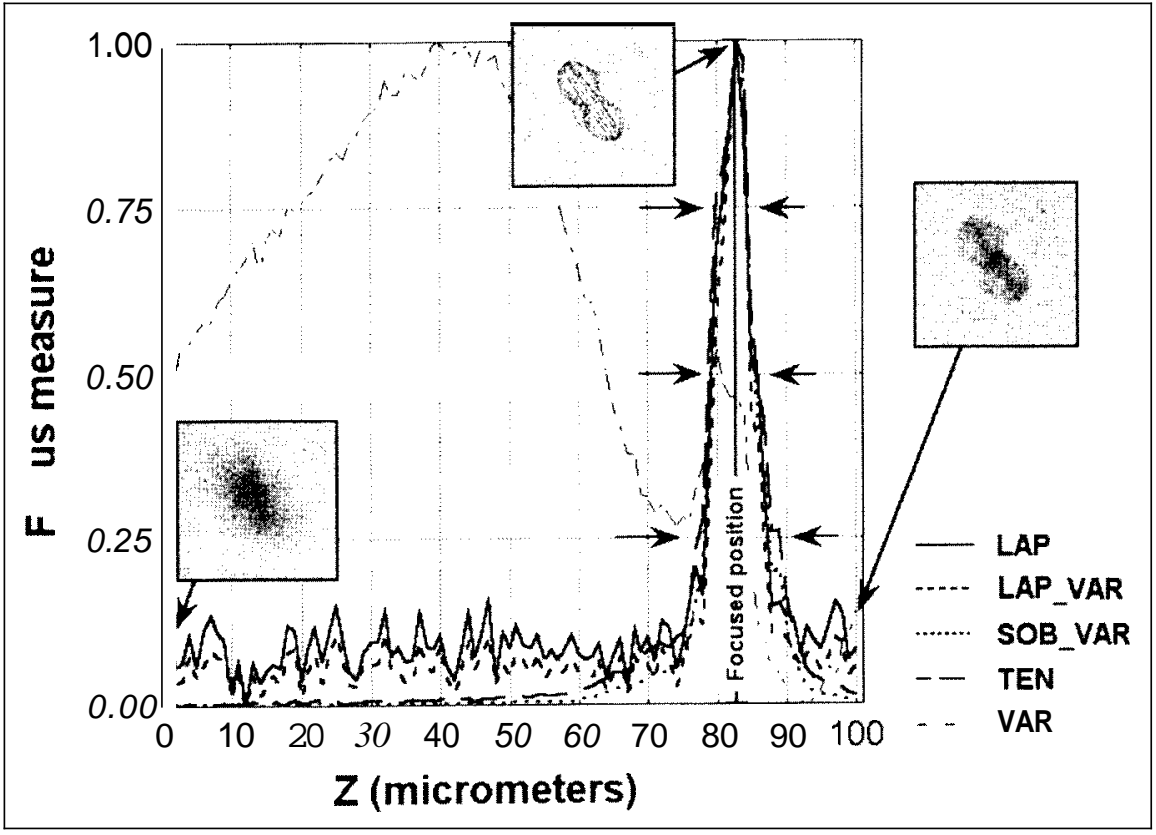

(b)

Figure 5. Focus measures (4 methods). (a) Without noise; (b) with noise. In (b) we have included also a variance measure for comparison purposes. LAP: Laplacian method; LAP-VAR: variance of Laplacian; SOB-VAR: variance of Sobel; TEN: Tenengrad. Medidas de foco (4 métodos). (a) Sin ruido (b) Con ruido. En (b) hemos incluido tambitn una medida de la variunza a efectos de comparación. LAP: método Laplaciano; LAP-VAR: varianza de la Laplaciana; SOB-VAR: variunza de Sobel; TEN: Tenengrad. 
where $g_{x}(n, m)$ and $g_{y}(n, m)$ are the convolutions with the kernels:

$$
S_{x}=\left(\begin{array}{lll}
-11 & 0 & 1 \\
-2 & 0 & 2 \\
-11 & 0 & 1
\end{array}\right) \quad S_{y}=\left(\begin{array}{ccc}
1 & 2 & 1 \\
0 & 0 & 0 \\
-1 & -2 & -11
\end{array}\right)
$$

respectively.

For each image in the stack, the Tenengrad method provides a focus measure given by:

$$
f m_{k}^{(i}=\sum_{m} \sum_{n}\left[g_{k}(n \cdot m)\right]^{2}
$$

The best focused image will be given by the maximum of $\mathrm{fm}_{k}{ }_{k}$.

\section{Laplacian and variance of Laplacian magnitude}

These techniques are similar to those using gradient magnitudes but with a second derivative operator. We use the Laplacian, with the convolution kernel:

$$
L=\frac{1}{6}\left(\begin{array}{ccc}
0 & -1 & 0 \\
-1 & 4 & -1 \\
0 & -1 & 0
\end{array}\right)
$$

The algorithms are based on computing only the absolute value of Laplacian or the variance of the Laplacian operator. Figure 5 a shows an example of an image stack above and below the best focused image located at the centre of the panel. Figure $5 \mathrm{~b}$ shows the autofocusing curves but for noisy images. We used a combination of variance and gradient methods in order to improve the sharpness and smoothness of the focusing curves. The sharpness measure on Sobel+variance is better than that based on Tenengrad. where as the smoothness measures are comparable (Pech-Pacheco et al., 2000).

\section{Multi-focusfusion techniques}

Since diatoms have a 3 -D valve we are investigating fusion-based methods for combining dif- ferent focal planes. We applied image fusion techniques after autofocusing for merging in a single plane the focused parts from planes neighbouring the best focused image. The fusion method was derived from a study of the spectral contents of images and provides a fast and efficient method to gather focused information from other planes. From this study we conclude that only $25 \%$ of the images in the stack (from both sides of the maximum or the autofocusing curves in figure 5 ) entail the most significant energy in the recombination process. This produces a contrast enhanced fused image where the fine diatom striae become more visible. Our autofocusing method provides a fast and accurate estimate of the best focused image. The autofocusing method was designed to provide not only the best image in focus but also to provide the recombination of multifocus images. These features distinguish the current approach from other alternative autofocusing methods, such as the correlation techniques described in Carnicer (1997). Figure 6 shows an example of a multifocus fusion process from a reduced set of eight images.

\section{PARTICLE IDENTIFICATION}

Once particles have been located, it is necessary to perform either an identification or a registration process. For the latter a comparison between two or more images is required (Lee et al., 1988; Lee et al., 1989; Lee et al., 1999; Smith \& Nandhakumar, 1996; Voss et al., 1999; Yeshurun \& Schwartz, 1989). The differences in rotation and scale are used in manual or automatic registration for comparison purposes or for 3D reconstruction. Image identification needs to be accomplished irrespectively of changes in scale and rotation. A number of different invariant identification methods have been proposed in the literature. However, most of them lack of robustness for different scale or rotation changes (Garcia-Martinez et al., 2000; Jurie, 1999; Leclerc, 1989; Reddy \& Chatterjii, 1996; Shark et al., 1998; Sweeney et al., 1987; Thornton \& Sangwine, 1999). Cepstrum analysis (log of spectrum) has been used in the 


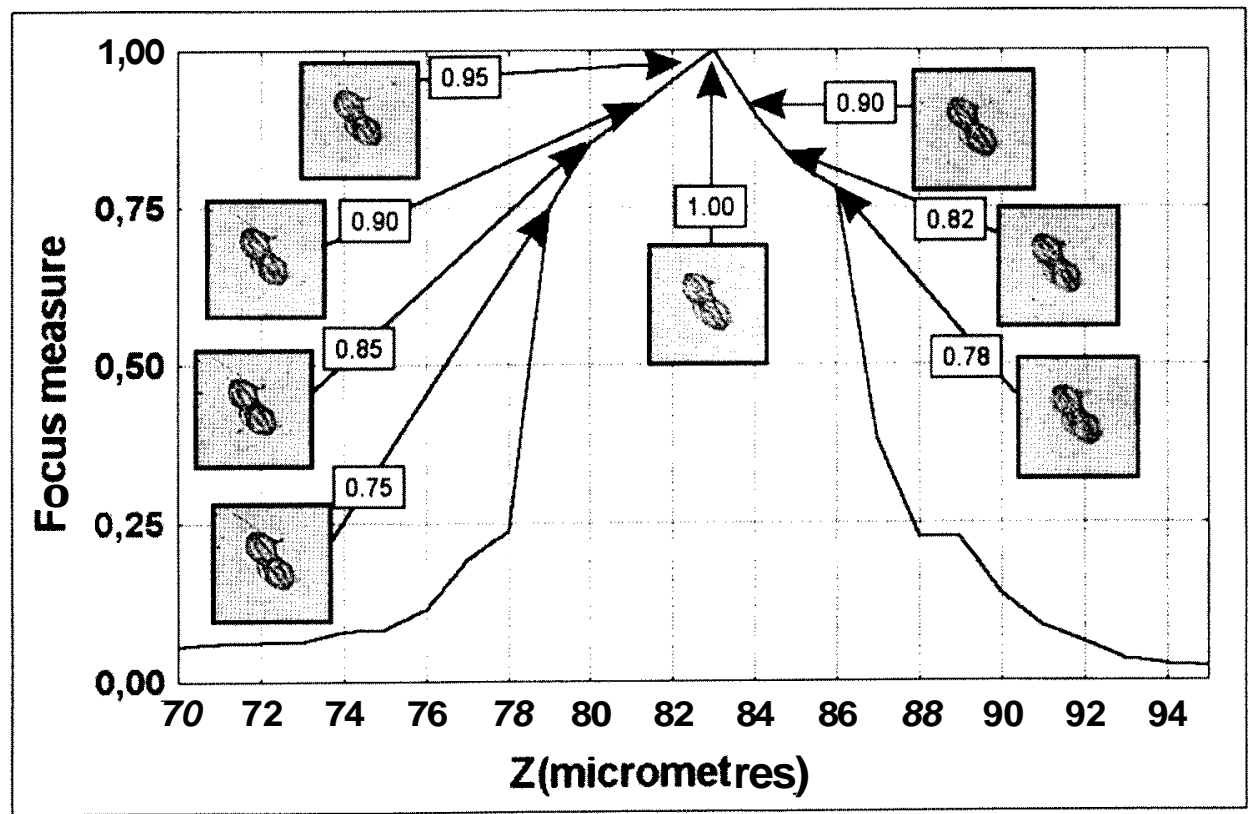

(a)

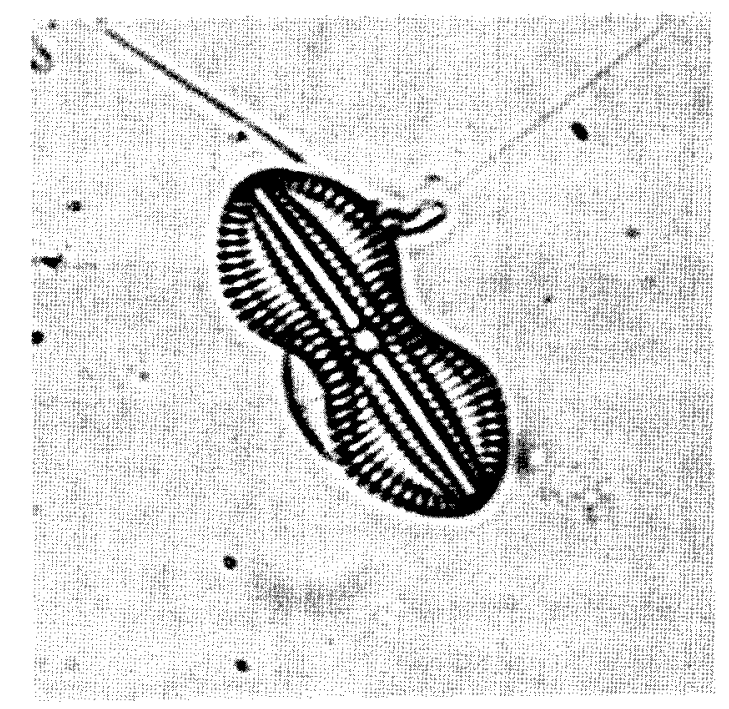

(b)

Figure 6. (a) Schematic representation of the multifocus fusion technique. Only the images located at the top quarter of the focus measure curve contribute to the fusion process (see text for details); (b) Fused image as result of the recombination process of the eight images showed in (a). (a)Representación esquematica de la técnica defusidn multifoco. Sólo las imagenes situadas en la cuarta parte superior de la curva de desenfoque intervienen en el proceso defusidn (ver el texto para mas detalles); (b) Imagen fusionada resultante del proceso de recombinación de las ocho imágenes representadas en laparte $(a)$. 
past for acoustic image processing, Doppler analysis and image registration. However, there are few works on the use of cepstrum techniques for image registration of scaled and rotated images (Lee et al., 1988; Lee et al., 1989; Smith \& Nandhakumar, 1996; Yeshurun \& Schwartz, 1989). Let us describe the basics of the scale transform.

\section{The scale transform}

We want a transform that will remove the magnification or rotation factors so that we may compare the inherent differences. The scale transform gives a transform insensitive to scaling or rotation. Thus, we can use the scale transform properties for image identification and registration. If we call $\mathrm{c}$ the scale variable the scale transform and its inverse are defined as (Cohen, 1993; Cristobal \& Cohen, 1996):

$$
\begin{aligned}
& D(c)=\frac{1}{\sqrt{2 \pi}} \int_{-\infty}^{\infty} f(x) \frac{e^{-j c \ln x}}{\sqrt{x}} d x \\
& f(x)=\frac{1}{\sqrt{2 \pi}} \int_{-\infty}^{\infty} D(c) \frac{e^{j c \ln x}}{\sqrt{x}} d c
\end{aligned}
$$

The scale transform can be written as

$$
D(c)=\frac{1}{\sqrt{2 \pi}} \int_{0} f(x) x^{-j-1 / 2} d x
$$

which shows that it is the Mellin transform with the complex argument $-j \mathrm{c}+1 / 2$. The Fourier-Mellin transform was introduced by Casasent \& Psaltis (1976), for rotation and scale invariant pattern recognition. Also, Altes used it to study mammalian hearing 1978. A practical realization of the Mellin transform is given by a logarithmic mapping of the input scene followed by a Fourier transform. There is strong physiological and psychophysical evidence of such log-polar mappings between the retina and the visual cortex in many visual sistems (including the human) (see Schwartz (1994) for a thorough review).
Since we are dealing with the Mellin transform of a complex argument, a direct relationship exists with the Fourier transform. In particular if we define a signal

$$
f_{l}=\frac{1}{\sqrt{x}} f(\ln x)
$$

then by substituting in Eq. 9 we have

$$
D_{l}(c)=\frac{1}{\sqrt{2 \pi}} \int_{-\infty}^{\infty} f(x) e^{-j c x} d x
$$

that is, $F(c)=D_{1}(c)$. From these relations one can identify the scale by resampling the uniformly distributed samples with a logarithmic function. The simplest way to construct multidimensional scale transforms is through $1 \mathrm{D}$ ones. In $2 \mathrm{D}$, one can define two feasible constructions, namely, separable and non separable implementations. The former corresponds to the successive application of 1D transforms along the XY Cartesian coordinates, while the latter is based on a warping operation converting the original spatial image onto Cartesian polar-logarithmic coordinates.

The non-separable direct 2D scale transform is given by

$$
D\left(c_{r}, c_{\theta}\right)=\frac{1}{\sqrt{2 \pi}} \int_{0}^{\infty} \int_{0}^{2 \pi} f(r, \theta) r^{-j c_{r}-1 / 2} e^{-j c_{\theta} \theta} d r d \theta
$$

and taking the $\log$ of the radial coordinate $\lambda=$ $\ln (r)$ we obtain

$$
D\left(c_{\lambda}, c_{\theta}\right)=\frac{1}{\sqrt{2 \pi}} \int_{0}^{\infty} \int_{0}^{2 \pi} e^{\lambda / 2} f(\lambda, \theta) e^{-j\left(\lambda c_{r}+\theta_{\theta}\right)} d \lambda d \theta
$$

Figure 7 shows an example of a diatom image (Fig. 7a), scaled (Fig. 7f) and rotated (Fig. 7k). After completion of all required steps depicted in figure 7 we obtain a similar scale spectrum for the three images (Figs. 7e, $7 \mathrm{j}$ and $7 \mathrm{o}$ ) providing an identification method invariant to affine transformations. 


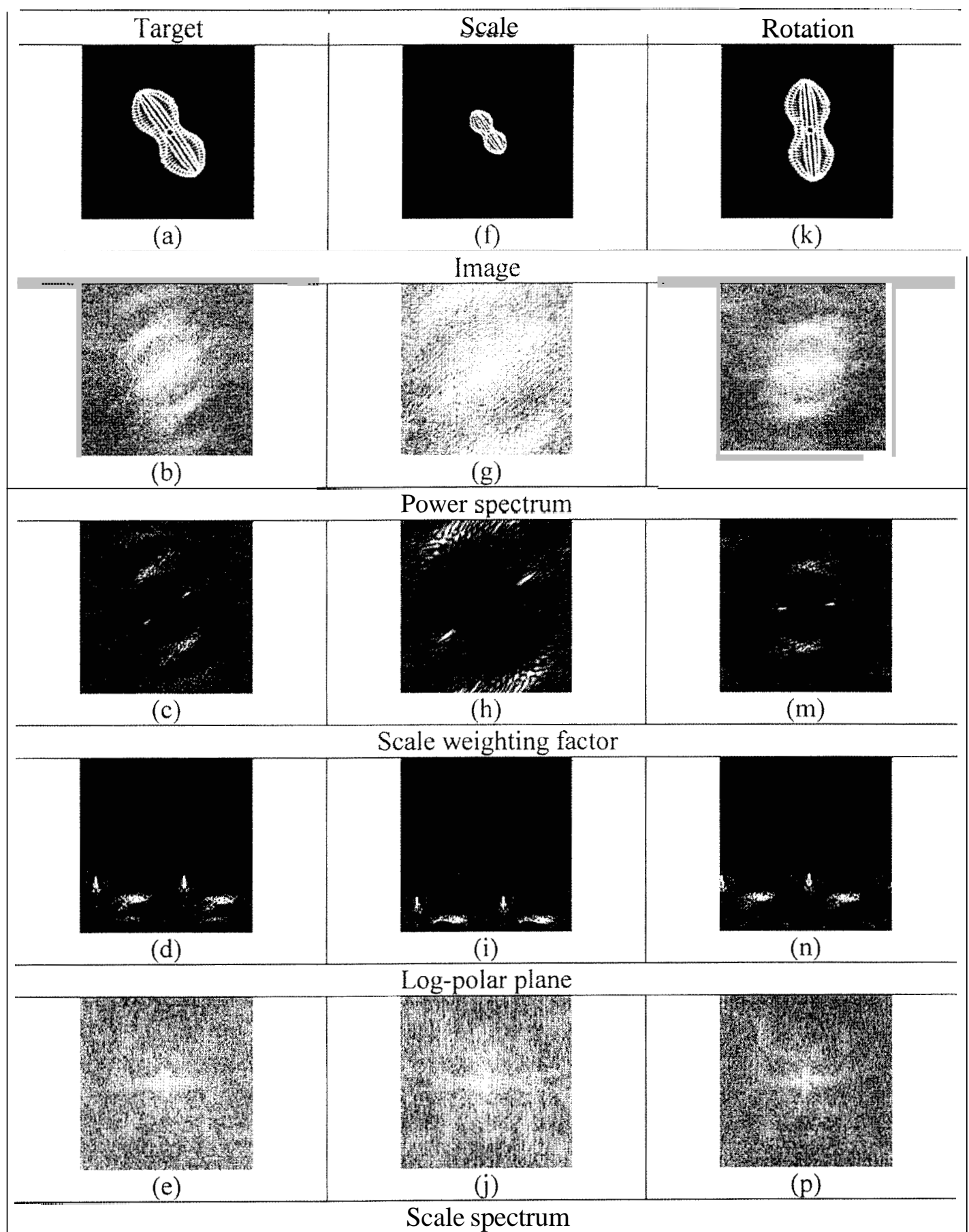

Figure 7. (a-e) Scale processing steps: (a) original image; (b) power spectrum (logarithmic visualization); (c) scale weighting factor; (d) logpolar plane; (e) scale spectrum. (f-j) Processing steps for scaled image, (k-o) Processing steps for rotation image. (a-e) Etapas del procesado de la escala (a)imagen original ( $b$ )espectro de potencia (visualización logarítmica); ( c factor de ponderación de escala; (d)plano log-polar (e) espectro de escala, (f-j) Etapas de procesado para una imagen cambiada de escala. (k-o)Etapas de procesado para una imagen rotada 


\section{Cepstral techniques: s-cepstrum a scale-based cepstrum}

The method we propose consists in calculating the cepstrum of the scale transform in order to improve pattern discrimination and robustness to noise. Figure 8a shows the scale spectrum steps and figure $8 \mathrm{~b}$ shows the cepstral cross-correlation steps. The power cepstrum (to avoid confusion with the complex cepstrum) is usually defined as the power spectrum of the logarithm of the power spectrum of a function (Childers, 1977). Here we propose a useful cepstral system for both registration and identification based on the use of the scale transform followed by a cepstral analysis. Thus, we can propose a new term called "s-cepstrum". where the "s" comes from scale.

\section{Diatom identification}

For diatom identification it is necessary to start with the scale spectrum (I-output in Figure 8a). The cepstrum module is similar as the one in the previous paragraph. The difference in the cross-correlation peaks provides a similarity measure between reference and test images. Aside from the cepstral cross-correlation (CCC) technique described in figure 8 , we have considered two other methods already proposed in the literature. The first is called the classical cross-conelation (NCC) technique and differs from the previous in that only the squared root of the Fourier transform is computed (Fig. 8b). The third method is called the binary cross-correlation (BCC) and consists in binarizing the power spectrum in figure $8 \mathrm{~b}$. The mean power spectrum is taken as a suitable threshold value.

\section{RESULTS}

We present here the results obtained for phytoplankton identification using a CCC (cepstral cross-correlation) interclass discrimination study between different diatoms, both rotated and scaled. This procedure provides the best discrimination among all correlation methods

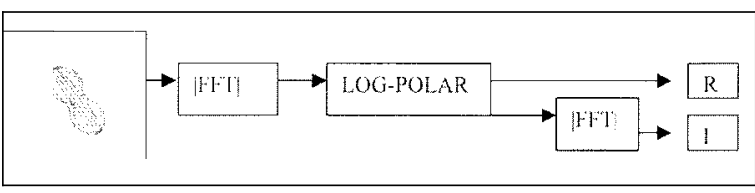

(a)

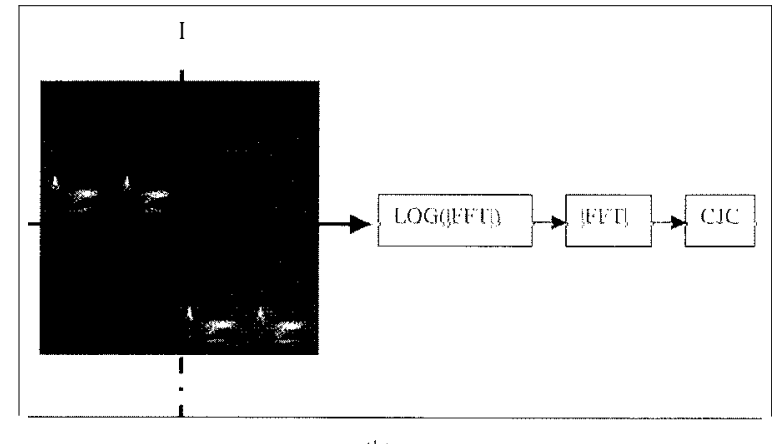

(b)

Figure 8. (a) General scheme for image identification (I) and registration (R). (b) The output of (a) constitutes the input for the cepstral joint correlation (CJC) for image identification (I,I') or registration (R,R'). (a) Esquema general para la identificación de imágenes (I) y registro ( $R$ ). (b) La salida de (a)constituye la entrada para la correlación cepstral conjunta $(C J C)$ en el proceso de identificación $\left(I, I^{\prime}\right)$ o registro $\left(R, R^{\prime}\right)$.

described above and a systematic testbed for ievaluating identification performance. For a comparison with other methods see PechPacheco et. al., (2000). We tested some power spectrum weighting factors (Gaussian, parabolic, etc) in order to improve the interclass discrimination. M4 and M7 modifiers correspond to the product of the magnitude of the Fourier spectrum with a parabolic and a Gaussian filter, respectively. M11 and M12 modifiers correspond to the same operators but using the magnitude squared. The problem here is to discriminate between different instances (1000 rotated and scaled diatoms per class) of class (a) and the same number of different instances of diatoms corresponding to classes (b) and (c). Figure 9 shows the results of the CCC method applied on diatoms depending on the selected weighting factor. In all cases we can observe a high inter- 


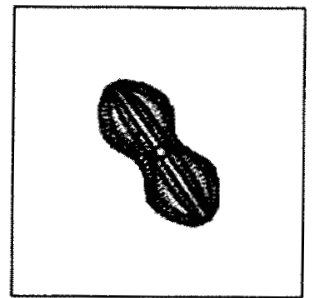

(A)

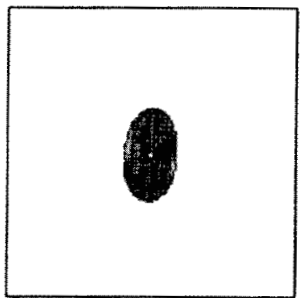

(B)

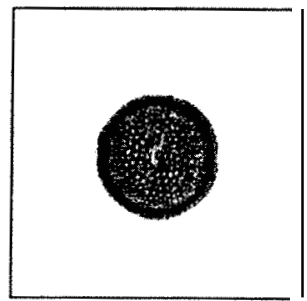

(C)

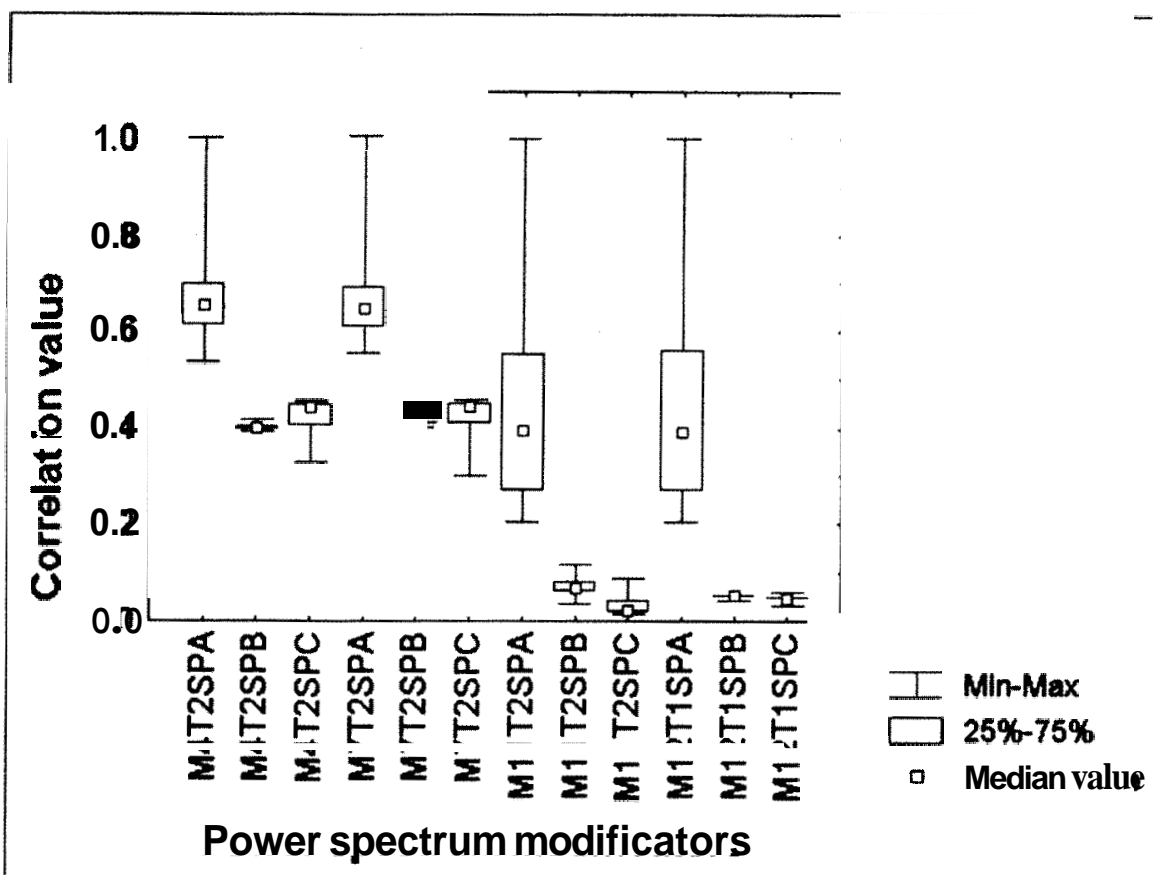

Figure 9. Interclass diatom identification for three diatoms labeled as A, B, C. Identificación interclase de diatomeas para las clases designadas con las letras $\mathbf{A}, \mathbf{B}$ y $\mathbf{C}$.

class discrimination between samples of diatom (a) (i.e. first box plot labeled M4T2SPA) and the rest of diatom samples, corresponding to diatoms (b) and (c) (i.e. second and third boxes labelled M4T2SPB and M4T2SPC, respectively). In other words, a clear separation exists between correlation values for class (a) and classes (b) and (c). A more complete analysis for validating the results, in collaboration with diatom experts is needed.

\section{CONCLUSIONS}

We have described a robust and efficient automatic slide scanning and autofocusing system in lighting microscopy. This study focuses on the 20-260 microns range (microplankton). The panoramic image (i. e. the mosaic) was generated with the $10 x$ objective, limiting the maximum size of the observed particles to 20 microns. In further studies, we intend to expand the present 
study to nannoplankton. The diatoms identified with this system are those showing the face of either the epivalve or the hipovalve of the frustule. Any other position of the particles could lead to missidentification. In the present study, all diatoms analyzed were correctly positioned on the slide. However, in further studies we intend to apply computer graphics algorithms to render the valve in $3 \mathrm{D}$ and therefore facilitate its identification in these abnormal cases. Also, it is necessary to take into account that both valves of some species (e.g. Cocconeis, Achnantes, etc) present different morphology. Therefore, we will consider the generation of different correlation filters for a better identification. We have shown two novel approaches in autofocusing based on a combination of gradient and variance processing. There is a wealth of work on autofocusing of large numbers of different specimens (PechPacheco et al., 2000). The proposed focus measures were compared with a number of techniques available in the literature. The method proposed here offers a significant performance improvement on other methods available thanks to new focusing metrics based on smoothness and peakedness.

Future research involves improving particle selection techniques and increasing the number of tested slide samples. A new cepstral power analysis has been proposed for image identification and registration. The approach is as follows. For registration, a log-polar cepstral cross-correlation technique has been used whereas for identification, the cepstral analysis has been performed on the power scale spectrum. The method is robust to affine transformations, outperforming other correlation-based methods as regarding interclass discrimination for gray-level diatom images and providing similar performance for binary images.

\section{ACKNOWLEDGMENTS}

This research is supported in part by the EU MAST3 ADIAC project. J.L. Pech-Pacheco thanks the CONACYT support. We thank Dr. M.
Bayer from The Royal Botanical Garden in Edinburgh, (UK) for providing some sample slides of diatoms.

\section{REFERENCES}

ALTES, R. 1978. The Fourier-Mellin transform and mammalian hearing. J. Acous. Soc. Am., 63(1): 174-183.

BOCKER, W., W. ROLF, W. MULLER \& C. STREFFER. 1996. Investigations about autofocusalgorithms for fluorescent-microscopy. SPIE Applications of Digital Image Processing XIX, Denver, CO, 2847: 445-456.

CAIRNS, J., K. DICKSON, G. LANZA, S. ALMEIDA, \& D. DEL BALZO. 1972. Coherent optical spatial filtering of diatoms in water pollution monitoring, Archiv. Mikrobiol., 83: 141-146.

CAIRNS, J., K. DICKSON, S. PRYFOGLE, S. ALMEIDA, J. FOURNIER \& H. FUJI. 1979. Determining the accuracy of coherent optical identification of diatoms. Water Resour. Bull., 15(6): 1770- 1775.

CARNICER, A., S. VALLMITJANA \& I. JUVELLS. 1997, Correlation post-processing based-method for the detection of defocused images, Appl. Optics., 36: 4807-4811.

CASASENT, D. \& D. PSALTIS. 1976. Position, rotation and scale invariant optical correlation. Appl. Opt., 15(7): 1795-1799.

CHILDERS, D., D. SKINNER \& R. KEMERAIT. 1977. The cepstrum: a guide to processing. IEEE Proc., 65(10): 1428-1443.

COHEN, L. 1993. The scale representation. IEEE Truns. Signal Processing, 41(12):3275-3292.

CRISTOBAL, G. \& L. COHEN. 1996. Scale in images. SPIE Proc., Denver, CO., 2846: 251-261. 1996.

CULVERHOUSE, P., R. SIMPSON, R. ELLIS, J. LINDLEY, T. WILLIAMS, T. PARISINI, B. REGUERA, I. BRAVO, R. ZOPPOLI, G. EARNSHAW, H. MACCALL \& G. SMITH. 1996. Automatic classification of field-collected dinoflagellates by artificial neural network. Mar: Ecol. Prog. Ser, 138: 281-287.

GARCIA-MARTINEZ, P., C. FERREIRA, J. GARCIA \& H. ARSENAULT. 2000. Nonlinear rotation-invariant pattern recognition by use of the optical morphological correlation. Appl. Optics, 39(5): 776-781. 
GROEN, F., I. YOUNG \& G. LIGTHARD. 1985. A comparison of different focus functions for use in autofocus algorithms. Cytometry, 6: 81-91.

JURIE, F. 1999. A new log-polar mapping for space variant imaging. application to face detection and tracking. Putt. Recog., 32: 865-875.

KINDRATENKO, V. 1997. Development and application of image analysis techniques for identification and classification of microscopic particles. $\mathrm{PhD}$ Thesis, Universiteit Antwerpen, Dept. Scheikunde, 190 pp.

KROTKOV, E. 1987. Focusing. Int. J. Comp. Vision, 1: 223-237.

LECLERC, L., Y. SHENG \& H. ARSENAULT. 1989. Rotation invariant phase-only and binary phaseonly correlation. Appl. Optics, 28(6): 1251-1256.

LEE, D. J., T. KRILE. \& S. MITRA. 1988. Power cepstrum and spectrum techniques applied to image registration. Appl. Optics, 27(6): 1099-1106.

LEE, D. J., S. MITRA \& T. KRILE. 1989. Analysis of sequential complex images, using feature extraction and two-dimensional cepstrum techniques. $J$. Opt. Soc. Am. A, 6(6): 863-870.

LEE, J. S., K. KIM \& S. E. KIM. 1999. Digital JTC simulator for stereo vision system. SPIE Proc. Denver, CO, 3808: 445-456.

NAYAR, S. K.\& Y. NAKAGAWA. 1994. Shape from focus. IEEE Trans. on Putt. Anal. and Machine Intell., 16(8): 824-831.

PECH-PACHECO, J. L. \& J. ALVAREZ-BORREGO. 1998. Optical-digital system applied to the identification of five phytoplankton species. Mar. Biol., 132: 357-365.

PECH-PACHECO, J. L, J. ALVAREZ-BORREGO,E. ORELLANA-CEPEDA \& R. CORTESALTAMIRANO. 1999. Diffraction patterns applicability in identification of Ceratium species. $J$. Plankton Res., 21(8): 1455-1474.

PECH-PACHECO, J. L., G. CRISTÓBAL, J. CHAMORRO-MARTINEZ \& J. FERNANDEZVALDIVIA. 2000. Diatom autofocusing in lighting microscopy: a comparative study. Int. Conf. on Pattern Recognition, Barcelona, Spain, 318-321.

REDDY, B. \& B. CHATTERJI. 1996. An FFT-based technique for translation, rotation and scale-invariant image registration. IEEE Trans. on Image Proc., 5(8): 1266-1271.
ROCKINGER, O. 1999. Multiresolution-Verfahren zur fusion dynumischer bildfolgen. PhD Thesis, Technischen Universitat Berlin, Alemania.

RUSS, J. 1995. The image processing handbook. CRC Press, Boca Raton, Florida.

SCHWARTZ, E. 1994. Topographic mapping in primate visual cortex: history, anatomy and computation. Visual Science and Engineering. Models and Applications. Ed. Marcel Dekker, New York.

SHARK, L., B. MATUSZEWSKI \& G. HALL. 1998. New template matching classification of viruses in electron microscope images. (online proceedings)http: //www.robots.ox.ac.uk/47\#47mvl/miua98/ abstract 17.html.

SMITH, P. \& N. NANDHAKUMAR. 1996. An improved power cepstrum based stereo correspondence method for textured scenes. IEEE Trans. on Putt. Anal. and Machine Intell., 18(3): 338-348.

SUBBARAO, M.\& A. NIKZAD. 1993. Focusing techniques. Opt. Eng., 32(11): 2824-2836.

SWEENEY, D., E. OCHOA \& G. SCHILS. 1987. Experimental use of iteratively designed rotation invariant correlation filters. Appl. Opt., 26(16): 3458-3465.

THORNTON, A. \& S. SANGWINE. 1999. Log-polar sampling incorporating a novel spatially variant filter to improve. Perception (22nd ECVP Proceedings) Trieste, Italy, 28: 147-151.

VOSS, K., H. SUESSE, H. ORTMANN \& T. BAUNBACH. 1999. Shift detection by restoration. Pattern Recog., 32: 2037-2068.

YEO, T., S. ONG, L. JAYASOORIAH \& R. SINNIAH. 1993. Autofocusing for tissue microscopy. Image and Vision Comp., 11(10): 629639.

YESHURUN, Y. \& E. SCHWARTZ. 1989. Cepstral filtering on a columnar image architecture: a fast algorithm for binocular stereo algorithm. IEEE Trans. on Putt. Analysis and Machine Intell., 11(7): 759-767.

ZACK, G., W. ROGERS \& S. LATT. 1977.Automatic measurement of sister chromatic exchange frequency. J. of Histochemistry and Cytochemistry, 25(7): 741-753. 